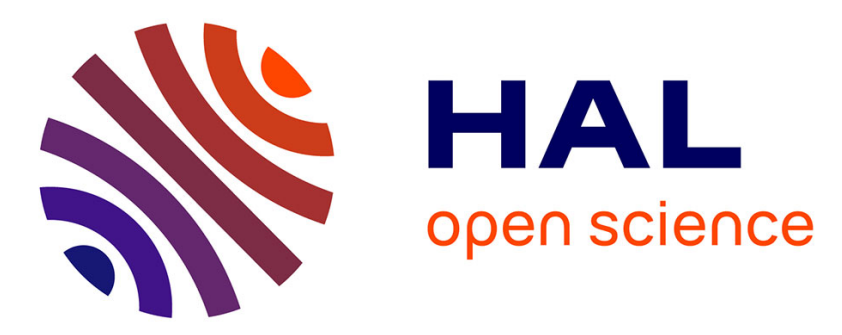

\title{
Modification of the magnetic properties of SmCo5 particles depending on the grinding atmosphere
}

\author{
Myrtil L. Kahn, Jean-Louis Bobet, François Weill, Bernard Chevalier
}

\section{To cite this version:}

Myrtil L. Kahn, Jean-Louis Bobet, François Weill, Bernard Chevalier. Modification of the magnetic properties of SmCo5 particles depending on the grinding atmosphere. Journal of Alloys and Compounds, 2002, 334 (1-2), pp.285-292. 10.1016/S0925-8388(01)01790-X . hal-00708242

\section{HAL Id: hal-00708242 \\ https://hal.science/hal-00708242}

Submitted on 12 Apr 2013

HAL is a multi-disciplinary open access archive for the deposit and dissemination of scientific research documents, whether they are published or not. The documents may come from teaching and research institutions in France or abroad, or from public or private research centers.
L'archive ouverte pluridisciplinaire HAL, est destinée au dépôt et à la diffusion de documents scientifiques de niveau recherche, publiés ou non, émanant des établissements d'enseignement et de recherche français ou étrangers, des laboratoires publics ou privés. 


\title{
Modification of the magnetic properties of $\mathrm{SmCO}_{5}$ particles depending on the grinding atmosphere
}

\author{
Authors : Kahn M., Bobet J.-L., Weill F., Chevalier B. \\ Published : Journal of Alloys and Compounds 2002, vol. 334, p. 285-292
}

\section{Introduction}

Magnetic nanostructures often exhibit behavior different from bulk materials [1]. Although there are many techniques for fabricating nanostructured materials, mechanical grinding has emerged as a unique method of producing disorder in alloys [2]. Ball milling is a high-energy deformation process that produces dislocations, vacancies, anti-site defects and strains. This technique has been widely developed in the 1960s and was used initially to strengthen the mechanical properties of alloys and to prepare compounds that could not be prepared using usual synthetic methods [3], [4] and [5]. The technique can be defined as a grinding process during which the powder is subjected to compression and traction forces leading to some plastic deformation, welds and fractures of the particles. The continuous repetition of these two latter phenomena (fracture and weld) leads to nanostructured materials.

The intermetallic compound $\mathrm{SmCO}_{5}$ belongs to a group of magnetic materials with hexagonal structure and a high magneto-crystalline anisotropy. These materials often show a high coercive force when powdered and are suitable for the production of permanent magnets [6]. The use of permanent magnets is of great interest for information storage devices. An increasing demand for miniaturization of the magnetic devices and for high-density storage has motivated research on small-sized particles. However, it is well documented that the magnetic properties are influenced by different characteristics such as size, crystallinity, and morphology of the particles which depend on their preparatory conditions [7] and [8].

The aim of this study was to investigate the influence of grinding on the magnetic properties of $\mathrm{SmCo}_{5}$ particles. More precisely, we studied the influence of the gaseous atmosphere ( $\mathrm{Ar}$ or $\mathrm{H}_{2}$ ) in order to achieve a better control of the magnetic properties when using the mechanical grinding technique. Our goal was to link both the structural characteristics and the morphology of the particles obtained by grinding to their magnetic properties.

\section{Experimental}

The intermetallic $\mathrm{SmCO}_{5}$ was prepared by melting of stoichiometric amounts of the constituent elements under a purified argon atmosphere in an induction levitation furnace. The purity of the starting materials was as follows: Sm, 99.9\%; Co, 99.99\%. Before milling, the powder was sieved at $100 \mu \mathrm{m}$ in a dry-box. $\mathrm{SmCo}_{5}$ particles were obtained by grinding using a Fritsch P5 high-energy apparatus. The ratio weight of ball over weight of sample is 15 and the rotation speed was fixed at $300 \mathrm{rpm}$. The diameter of the ball used for grinding is $10 \mathrm{~mm}$. The applied pressure of $\mathrm{H}_{2}$ was 1.1 MPa.

The samples were characterized by conventional X-ray powder diffraction using $\mathrm{Cu}$ Ka radiation. The particle size and morphology were investigated by scanning electron microscopy using a JEOL 840 microscope. The granulometer used was a Mastersizer 2000S instrument from Malvern working in a bichromatic diffraction or diffusion mode. The analysis was performed in a liquid medium (i.e. ethanol). Information on the chemical composition was obtained by microprobeX, using a Cameca SX100 apparatus. The TEM images were obtained with a JEOL 200FX microscope. Samples for dark field images were prepared by dispersion of particles in an EPON resin and cut into pieces of $75 \mathrm{~nm}$ thickness. Magnetization measurements were carried out using a MPMS-5S Quantum Design SQUID magnetometer. Particles were dispersed in eicosane in order to prevent any movement of the particles during the measurements. 


\section{Results}

\subsection{Structural properties of the particles}

All samples were characterized by microprobe-X. The elementary analysis revealed that the samples are homogeneous. The atomic proportion of the initial material corresponds to a 1:5 ratio of Sm and Co atoms, respectively. Fig. 1 shows the X-ray diffraction patterns of the $\mathrm{SmCO}_{5}$ particles as a function of grinding time under $\mathrm{Ar}$ (Fig. 1a) or under $\mathrm{H}_{2}$ (Fig. $\underline{1 b}$ ). The diffraction patterns of the initial compound exhibit sharp diffraction peaks corresponding to $\mathrm{SmCO}_{5} \mathrm{Compound}$ (hexagonal $\mathrm{CaCu}_{5}$ structure type, space group: $P 6 / \mathrm{mmm}$ ). Diffraction patterns of the samples ground under Ar present broadened peaks even after only 20 min of grinding. As the milling time increases, the peaks broaden and, finally an almost amorphous phase is obtained after $2 \mathrm{~h}$. On the other hand, diffraction patterns of the samples obtained under $\mathrm{H}_{2}$ start to become broadened only after $1 \mathrm{~h}$ of grinding. Moreover, the diffraction pattern obtained after the longer grinding time shows peaks of $\mathrm{SmH}_{2+\delta}$ (indicated by stars on Fig. 1b) which is indicative of the decomposition of the $\mathrm{SmCO}_{5}$ compound into samarium hydride and cobalt. To confirm this hypothesis and as Co cannot be detected by XRD with $\mathrm{Cu}$ K $\alpha$ radiation, experiments were performed using $\mathrm{Cr}$ K $\alpha$ radiation $(\lambda=2.28970 \AA$ ). The peaks relative to Co have been detected confirming the decomposition of $\mathrm{SmCo}_{5}$ into $\mathrm{SmH}_{2+\delta}$ and $\mathrm{Co}$.

The sizes of the coherent domains of the samples have been evaluated by transmission electronic microscopy in dark field mode. Fig. 2 shows pictures obtained for all samples and inserts correspond to the diffraction patterns. The picture of the starting material is presented in Fig. $2 a$ and corresponds to a monocrystalline particle as confirmed by the diffraction pattern. The pictures of the sample ground during 20 min under $\mathrm{Ar}$ or $\mathrm{H}_{2}$ are shown in Fig. 2b,c, respectively. Although the sample ground under $\mathrm{H}_{2}$ is still monocrystalline, the sample ground under Ar during the same time presents a totally different pattern. Indeed, Fig. $2 \mathrm{~b}$ shows a small well defined area of diffraction. The mean size of these areas is $15 \pm 5 \mathrm{~nm}$. The images of the samples ground during 1 and $2 \mathrm{~h}$ under $\mathrm{Ar}$ or $\mathrm{H}_{2}$ are shown in Fig. $2 \mathrm{~d}-\mathrm{g}$, respectively. For the same milling time, the shapes of the images are similar whatever the milling atmosphere. These pictures present well defined areas of diffraction with a mean size of $15 \pm 5 \mathrm{~nm}$.

\subsection{Size and morphology of the particles}

Table 1 reports the mean size $\left(d_{0.5}\right)$ and the span (i.e. the distribution size defined as $\left.\left(d_{0.8}-d_{0.2}\right) / d_{0.5}\right)$ measured by granulometry for samples obtained under $\mathrm{Ar}$ or $\mathrm{H}_{2}$. As a general trend, the particle size decreased as the grinding time increased to finally reach the same lower limit either for the samples ground under $\mathrm{Ar}$ or $\mathrm{H}_{2}$. Starting from a sample sieved at $100 \mu \mathrm{m}$, samples ground during $20 \mathrm{~min}$ under $\mathrm{Ar}$ and $\mathrm{H}_{2}$ have sizes of 81 and $69 \mu \mathrm{m}$, respectively. At 1 or $2 \mathrm{~h}$, the size of the particles is in the range 35-40 $\mu \mathrm{m}$. Increasing milling time up to $2 \mathrm{~h}$ does not lead to a decrease in the particle size. However, it leads to a decrease in the span (e.g. 1.13 after $1 \mathrm{~h}$ and 1.08 after $2 \mathrm{~h}$ for samples ground under $\mathrm{H}_{2}$ ).

The morphology of the particles has been studied by SEM. The particles of the starting material present well defined faces with sharp ridges (Fig. 3a). The sample ground during 20 min under $\mathrm{H}_{2}$ (Fig. 3b) presents, in addition to the previous particles, aggregations of the smallest particles. The latter, however, are present as minor species. The proportions are reversed for the sample ground for $1 \mathrm{~h}$ under $\mathrm{H}_{2}$ (Fig. $3 \mathrm{c}$ ) whereas the sample ground for $2 \mathrm{~h}$ under $\mathrm{H}_{2}$ is mostly composed of aggregates of particles (Fig. 3d). One feature of the particles ground under $\mathrm{H}_{2}$ during 20 min is to present fractures as shown in Fig. 4. Such fractures have only been observed for samples ground under $\mathrm{H}_{2}$. The samples ground under Ar present a different trend. Indeed, for a grinding time of $20 \mathrm{~min}$, the sample is already mostly composed of aggregates. No major modification in the morphology of the particles is observed for longer grinding times. The main difference between samples ground under $\mathrm{Ar}$ or $\mathrm{H}_{2}$ is observed for a grinding time of 20 min (for comparison, see Fig. 3e).

\subsection{Magnetic properties}

The magnetization versus field curves for the samples ground under $\mathrm{Ar}$ or $\mathrm{H}_{2}$ are shown in Fig. $5 a$,b, respectively. Values of the coercivity and the saturation magnetization are reported in Table 2. The starting material exhibits a coercivity of $0.4 \mathrm{~T}$ and a saturation magnetization of $60 \mathrm{emu} \cdot \mathrm{g}^{-1}$. The samples ground under Ar present the following trend: for a grinding time of $20 \mathrm{~min}$, the coercivity increases to reach $1.6 \mathrm{~T}$ and the saturation magnetization is constant (60 
emu $\left.\cdot \mathrm{g}^{-1}\right)$. As the grinding time increases to 1 and $2 \mathrm{~h}$, the coercivity decreases, $H_{\mathrm{C}}=1.0$ and $0.6 \mathrm{~T}$, and the saturation magnetization increases, $M_{\mathrm{s}}=71$ and $73 \mathrm{emu} \cdot \mathrm{g}^{-1}$, respectively. The samples ground under $\mathrm{H}_{2}$ present a different trend: for a grinding time of $20 \mathrm{~min}$, the coercivity is equal to $0.7 \mathrm{~T}$ and the saturation magnetization is equal to $60 \mathrm{emu} \cdot \mathrm{g}^{-1}$. As the grinding time increases to 1 and $2 \mathrm{~h}$, the coercivity decreases and the saturation magnetization increases (e.g. $H_{\mathrm{C}}=0.4$ and $0.0 \mathrm{~T}$, and $M_{\mathrm{S}}=71$ and $91 \mathrm{emu} \cdot \mathrm{g}^{-1}$, respectively). If the hysteresis loops of the sample ground during $1 \mathrm{~h}$ start to present a large coercivity, a shoulder around $\pm 1.5 \mathrm{~T}$ leads to a value of coercivity close to the value observed for the starting material.

\section{Discussion}

In the present study, our goal was to control the magnetic properties of $\mathrm{SmCo}_{5}$ particles using the grinding method. These properties depend greatly on the structural and morphological characteristics of the material. Then, the control of the magnetic properties requires the identification of the relationship between the grinding conditions and the structural and morphological properties. From the results presented in the previous section, we can make the following observations.

When the samples are ground under $\mathrm{Ar}$ or $\mathrm{H}_{2}$, they are homogeneous and correspond to the phase $\mathrm{SmCo}_{5}$ at least for a grinding time up to $1 \mathrm{~h}$. For a longer grinding time under $\mathrm{H}_{2}$, the $\mathrm{X}$-ray diffraction pattern reveals a decomposition into $\mathrm{SmH}_{2+\delta}$ and $\mathrm{Co}$. The grinding under Ar leads to a faster amorphization of the sample in comparison to the grinding under $\mathrm{H}_{2}$. It is important to note that the crystallinity of the sample is strongly correlated with the experimental conditions and in particular depends on the size of both the balls and the container (which are constant here). The evolution of the crystallinity of the samples is confirmed by the TEM pictures allowing the determination of the size of the coherent domains of diffraction. It appears that as soon as the amorphization begins, the size of the coherent domains of diffraction reaches a value of $15 \pm 5 \mathrm{~nm}$ whatever the grinding conditions. It seems that this value corresponds to the lower size limit of the coherent domains of diffraction in the grinding conditions we used.

Whatever the milling atmosphere, the energy of grinding is used to reach amorphization of the sample. Under Ar, there is only one source of energy which comes from the grinding. However, $\mathrm{SmCO}_{5}$ absorbs hydrogen under only $0.4 \mathrm{MPa}$ at room temperature and this reaction is exothermic [9]. Consequently, under $\mathrm{H}_{2}$, there are two sources of energy, one coming from the grinding and the second coming from the formation of the $\mathrm{SmCO}_{5}$ hydride. This thermal effect could be the origin of the difference of crystallinity of the sample for short grinding time.

The decomposition of the $\mathrm{SmCO}_{5}$ particles into $\mathrm{SmH}_{2+\delta}$ and $\mathrm{Co}$ involves the intermediate compound, $\mathrm{SmCo}_{5} \mathrm{H}_{2.9}$. This pathway has been evidenced by the SEM picture showing a straight fracture in the particle (Fig. 4). Indeed, during the grinding, a series of fractures and welds occur. The type of the fracture, brittle or ductile, depends on the nature of the material. Intermetallic compounds like $\mathrm{SmCO}_{5}$ should present a ductile type behavior. However the fracture observed in the SEM picture is characteristic of a brittle-type behavior indicating the formation of the hydride $\mathrm{SmCo}_{5} \mathrm{H}_{2.9}$.

Moreover, this decomposition is indicative of the relative stability of the hydrides. For $\mathrm{SmCo}_{5} \mathrm{H}_{2.88}$, the enthalpy and entropy, $\Delta H$ and $\Delta S$, are equal to $-34.95 \mathrm{~kJ} \mathrm{~mol}^{-1}$ and $-0.129 \mathrm{~kJ} \mathrm{~mol}^{-1} \mathrm{~K}^{-1}$, respectively [9]. The corresponding values for $\mathrm{SmH}_{2}$ compound are $-186.88 \mathrm{~kJ} \mathrm{~mol}^{-1}$ and $-0.115 \mathrm{~kJ} \mathrm{~mol}^{-1} \mathrm{~K}^{-1}[10]$. If the values of $\Delta S$ are close, the $\Delta H$ values are different: the $\Delta H$ value of $\mathrm{SmH}_{2}$ is more than five times higher (in absolute value) than the $\Delta H$ value of $\mathrm{SmCo}_{5} \mathrm{H}_{2.9}$. It clearly appears that $\mathrm{SmH}_{2+\delta}$ is much more stable than $\mathrm{SmCo}_{5} \mathrm{H}_{2.9}$. Moreover, the decomposition of the sample into $\mathrm{SmH}_{2+\delta}$ and $\mathrm{Co}$ under $\mathrm{H}_{2}$ after $2 \mathrm{~h}$ of grinding is in agreement with reported results for alloys of $\mathrm{Sm}\left(\mathrm{Co}_{1-x} \mathrm{Cu}_{x}\right)_{2}$ which disproportionates at $693 \mathrm{~K}$ into $\mathrm{SmH}_{2}$, $\mathrm{Co}$ and $\mathrm{Cu}$ under $\mathrm{H}_{2}$ without grinding [11].

The magnetic properties observed in both series of compounds are, as expected, strongly linked to the composition, crystallinity and morphology of the particles. For samples ground under Ar, we observed a faster amorphization but no decomposition. This amorphization leads to the creation of defects in the structure. These defects correspond to pinning points of the magnetization that are responsible for the enlargement of the hysteresis loop. For longer grinding times, the sample transforms from a hard magnet (crystalline) to a soft magnet (amorphous) leading to a decrease in the coercivity of the material. Such trends have already been observed for $\mathrm{SmCO}_{5}$ when grinding under inert atmosphere [7]. However, Leslie-Pelecky and Kirkpatrick observed that the decrease in the coercivity occurs for grinding times longer than $2 \mathrm{~h}$. Moreover, the samples are still crystalline after $2 \mathrm{~h}$ of grinding. These differences could come 
from the grinding conditions. For example, in the reported paper [7], the mill was a Spex 8000 whereas in our case we used a Fritsch P5. Indeed, it is well known that the results obtained by energetic grinding methods depend on numerous parameters like the type of the mill, the number of balls, their diameter, the speed of rotation and so on. These differences in the grinding method lead to different distributions of energy and hence to different results.

For samples ground under $\mathrm{H}_{2}$, the magnetic behavior is governed by the decomposition of the material into $\mathrm{SmH}_{2+\delta}$ and Co. Indeed, for short grinding times, no major differences in the crystallinity and morphology of the particles are observed implying no important modifications of the magnetic properties. For $1 \mathrm{~h}$ of grinding, the hysteresis loop corresponds to the superposition of two behaviors, one coming from the hard magnet $\mathrm{SmCO}_{5}$ and the second from the soft magnetic $\mathrm{Co}$, the $\mathrm{SmH}_{2+\delta}$ compound at $270 \mathrm{~K}$ being non-magnetic. After $2 \mathrm{~h}$ of grinding, the material consists of $\mathrm{SmH}_{2+\delta}$ and $\mathrm{Co}$ and the magnetic properties correspond to the soft magnetic $\mathrm{Co}$.

Clearly, this study shows that the magnetic properties depend greatly on the grinding conditions. The grinding method allows modification of the magnetic properties of particles. As a general trend, grinding under $\mathrm{Ar}$ or $\mathrm{H}_{2}$ leads to the same evolution of the magnetic properties starting with an increase in the coercivity due to the creation of defaults and then to a decrease in the coercivity due to the formation of a soft material (amorphous phase or Co metal). However, the increase in the coercivity obtained under $\mathrm{Ar}$ is much more important than that obtained under $\mathrm{H}_{2}$. Indeed, the grinding under $\mathrm{H}_{2}$ allows to obtain small particles but does not lead to the formation of the same defaults because of the difference in the distribution of energy. Consequently, grinding under $\mathrm{H}_{2}$ does not allow to increase considerably the coercivity of the material before its decomposition.

\section{Conclusion}

In summary, we synthesized $\mathrm{SmCO}_{5}$ particles using energetic grinding under two different gaseous atmospheres. Grinding under Ar leads to a faster amorphization. The samples ground under $\mathrm{H}_{2}$ are less stable and lead to the decomposition of $\mathrm{SmCO}_{5}$ into $\mathrm{SmH}_{2+\delta}$ and Co. In this study, we were able to establish the relationship between structural and morphological properties and the magnetic properties of the compounds. We show that depending on the grinding conditions, the magnetic properties are different. To conclude, the energetic grinding method appears to be a very efficient method to prepare nanostructured material with controllable magnetic properties.

\section{References}

1. R.H. Kodama, A.E. Berkowitz, E.J. McNiff, S. Foner. Phys. Rev. Lett., 77 (1996), p. 394

2. G.F. Zhou, H. Bakker. Phys. Rev. B, 52 (1995), p. 9437

3. J.S. Benjamin. Metall. Trans., 1 (1970), p. 2943

4. L. Lu, M.O. Lai, M.L. Hoe. Nanostruct. Mater., 10 (4) (1998), p. 551

5. J.-L. Bobet, S. Pechev, B. Chevalier, B. Darriet. J. Mater. Chem., 9 (1999), p. 315

6. H. Zijlstra, F.F. Westendorp. Solid State Commun., 7 (1969), p. 857

7. D.L. Leslie-Pelecky, E.M. Kirkpatrick. Nanostruct. Mater., 12 (1999), p. 887

8. W. Liu, P.G. McCormick. Nanostruct. Mater., 12 (1999), p. 187

9. J.J.G. Willems, K.H.J. Buschow. J. Less-Common Met., 129 (1987), p. 354

10. C. Ohki, M. Tada, Y.C. Huang, H. Uchida, H. Uchida. J. Less-Common Met., 103 (1984), p. 103

11. N.K. Zaikov, N.V. Mushnikov, A.E. Ermakov, A.K. Shtol'ts, A.V. Korolev. Fiz. Met. Metalloved., 88 (1999), p. 34 


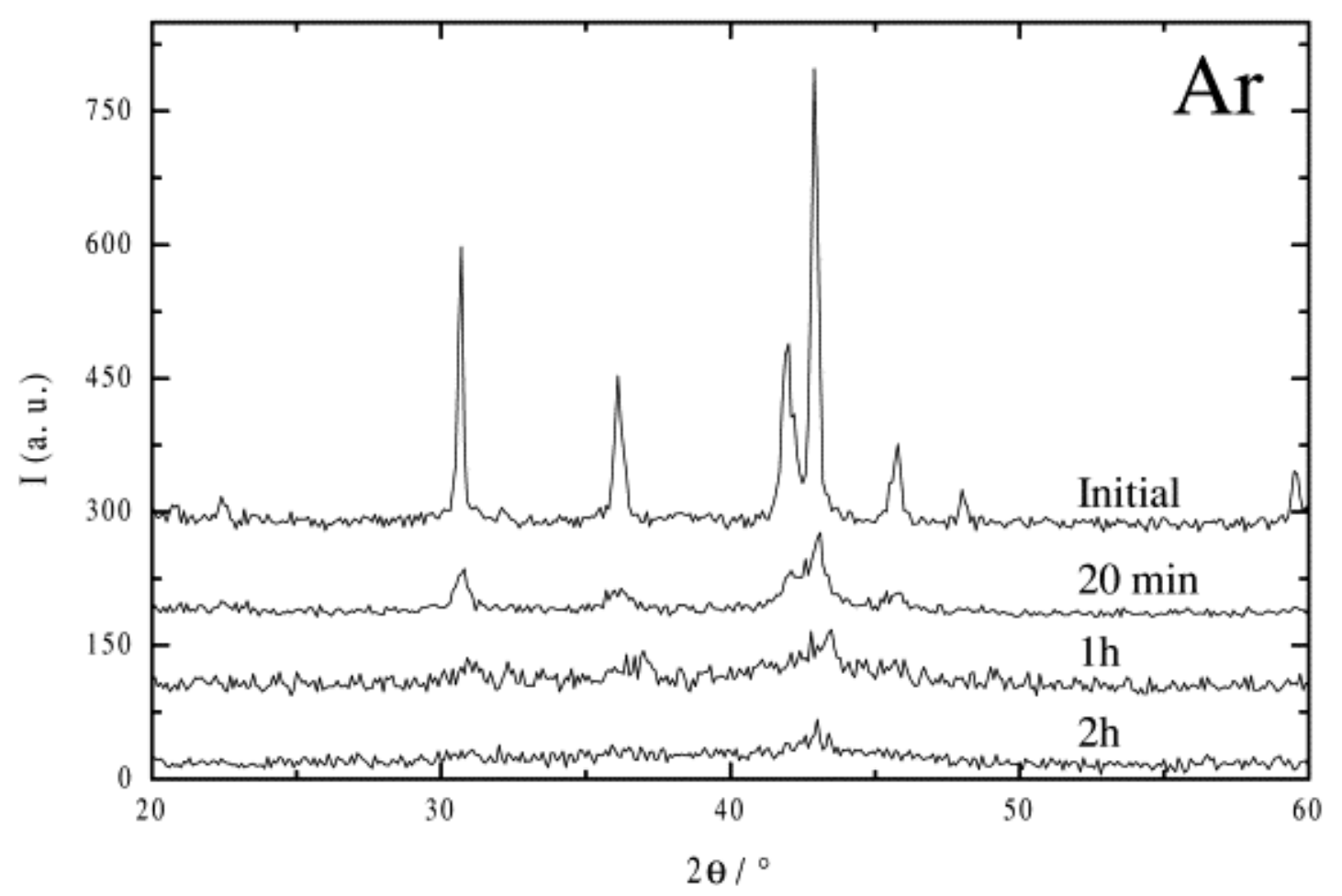

a

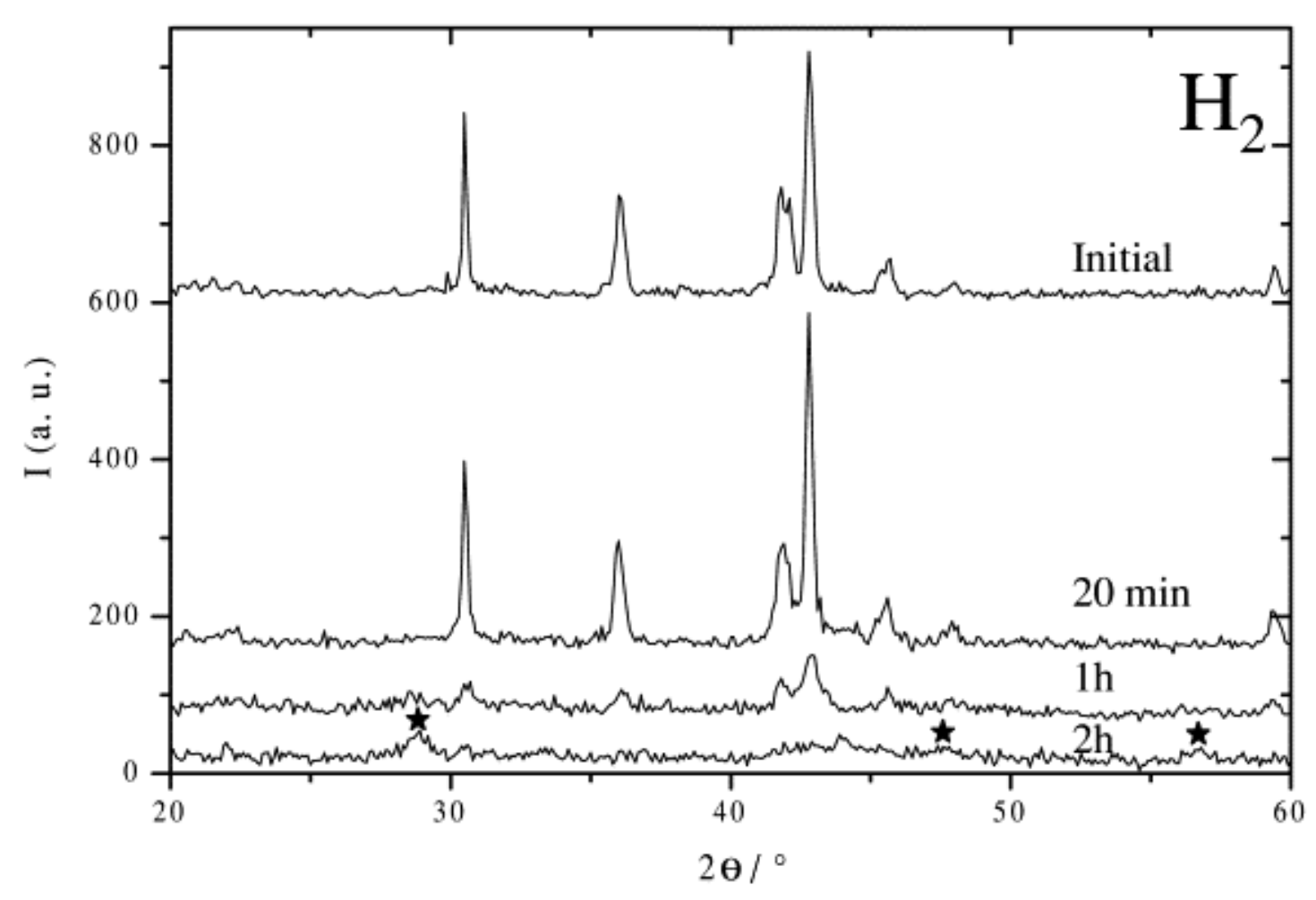

b

Fig. 1. X-Ray powder diffraction of $\mathrm{SmCO}_{5}$ particles ground under $\mathrm{Ar}(\mathrm{a})$ or $\mathrm{H}_{2}$ (b). Initial pattern reveals pure $\mathrm{SmCO}_{5}$ compounds. Star stands for $\mathrm{SmH}_{2+\delta}$ compounds. 

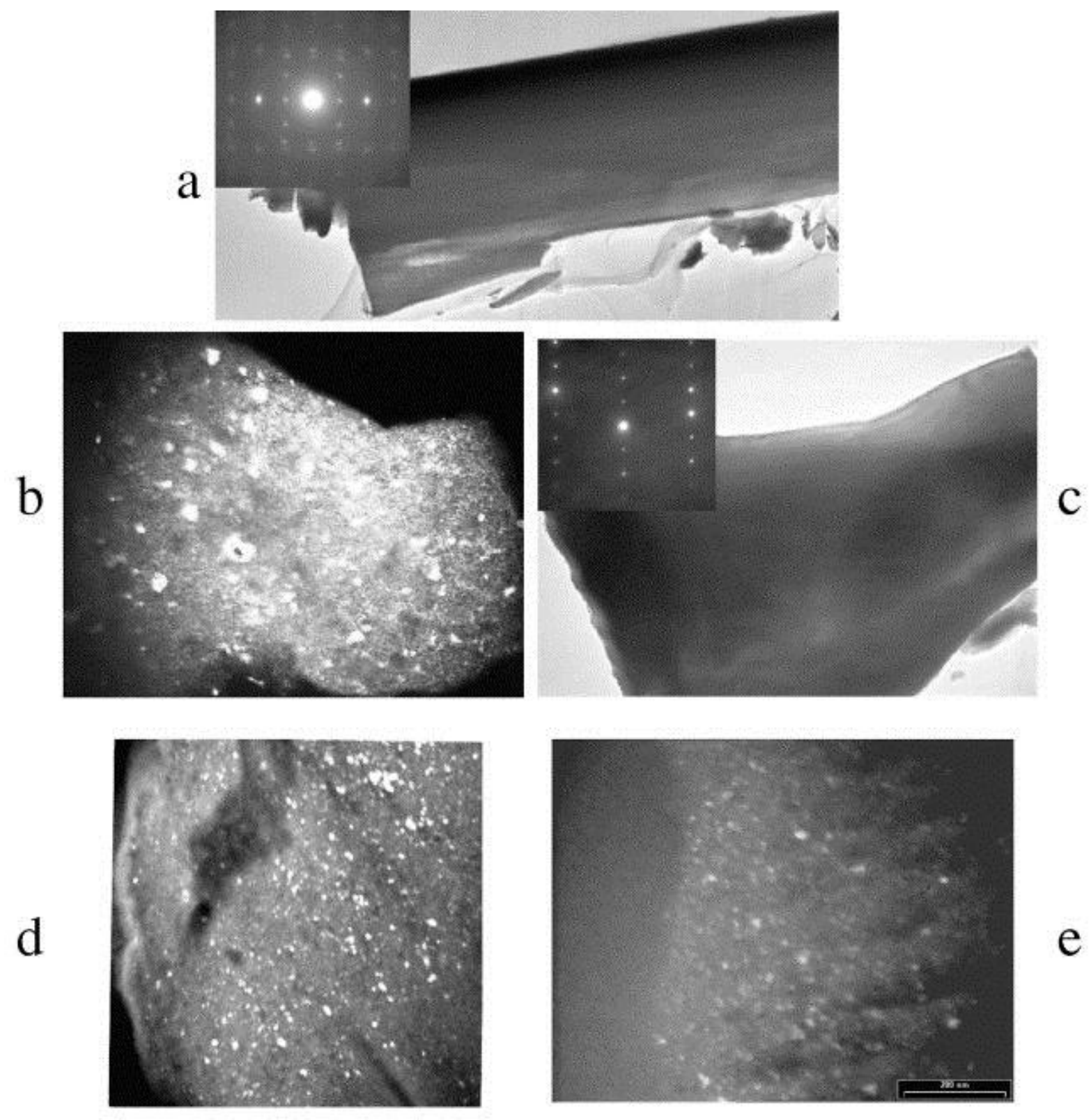

e

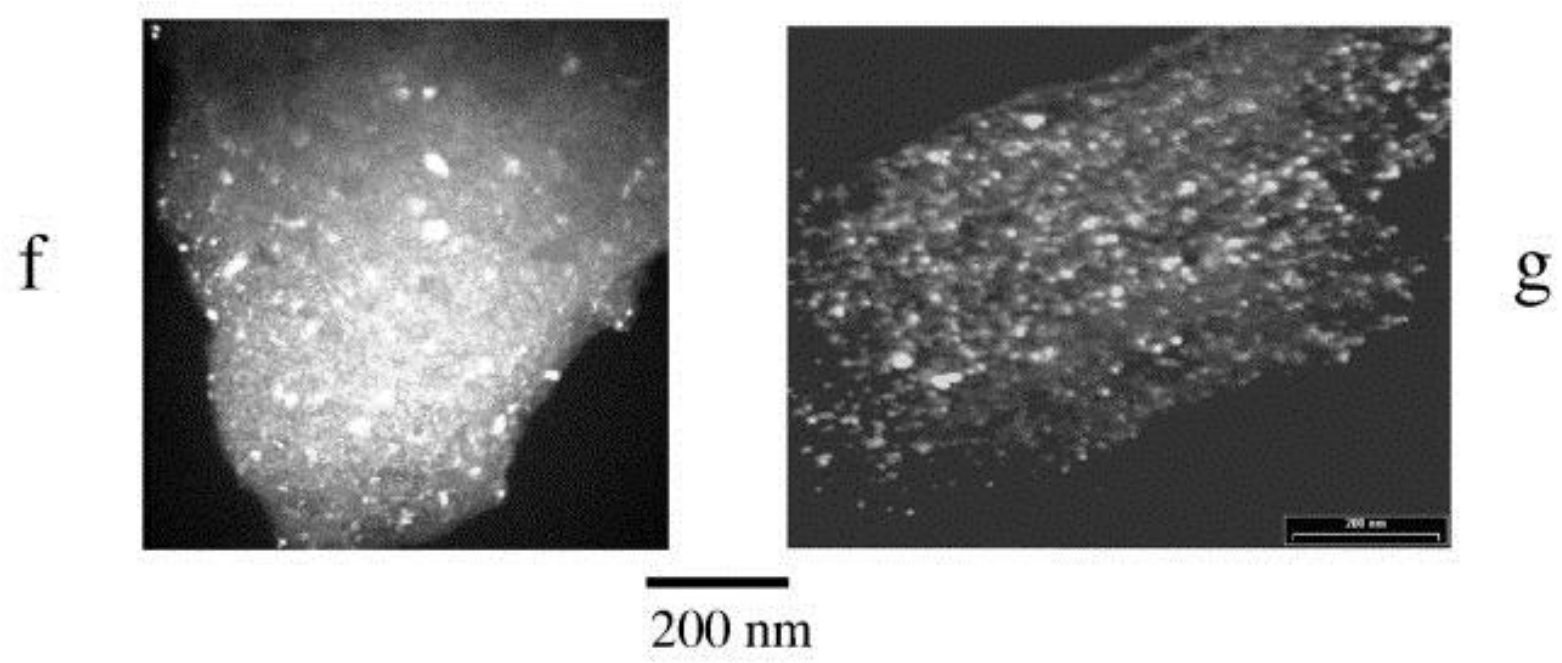

Fig. 2. TEM pictures of the coherent domains: initial material (a); ground under $\operatorname{Ar}(b)$ or $\mathrm{H}_{2}$ (c) for 20 min; ground under $\mathrm{Ar}$ (d) or $\mathrm{H}_{2}$ (e) for $1 \mathrm{~h}$; ground under $\operatorname{Ar}(\mathrm{f})$ or $\mathrm{H}_{2}$ (g) for $2 \mathrm{~h}$. 

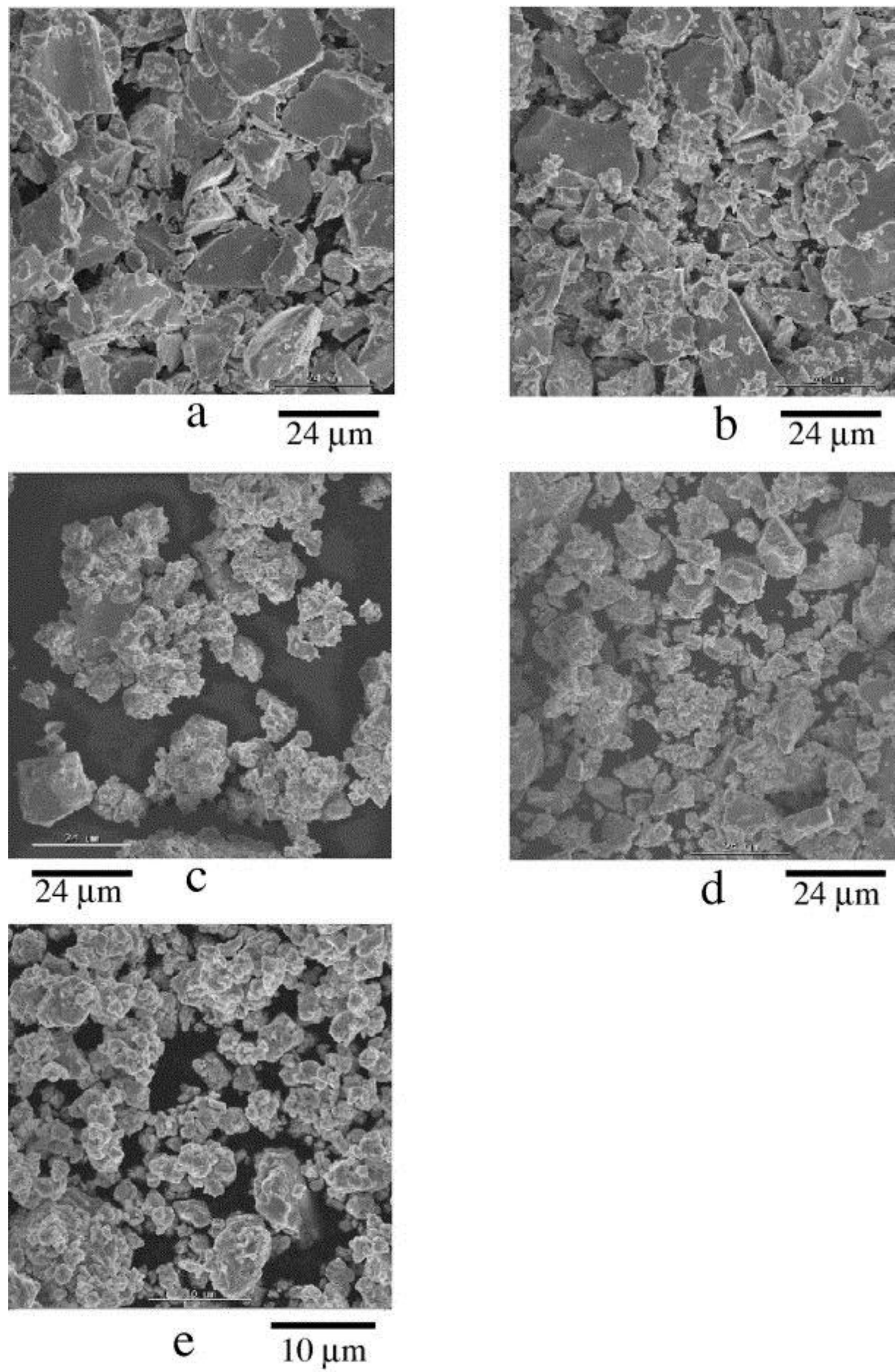

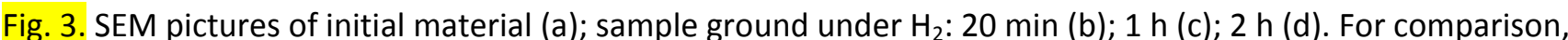
sample ground for 20 min under $\operatorname{Ar}(\mathrm{e})$. 


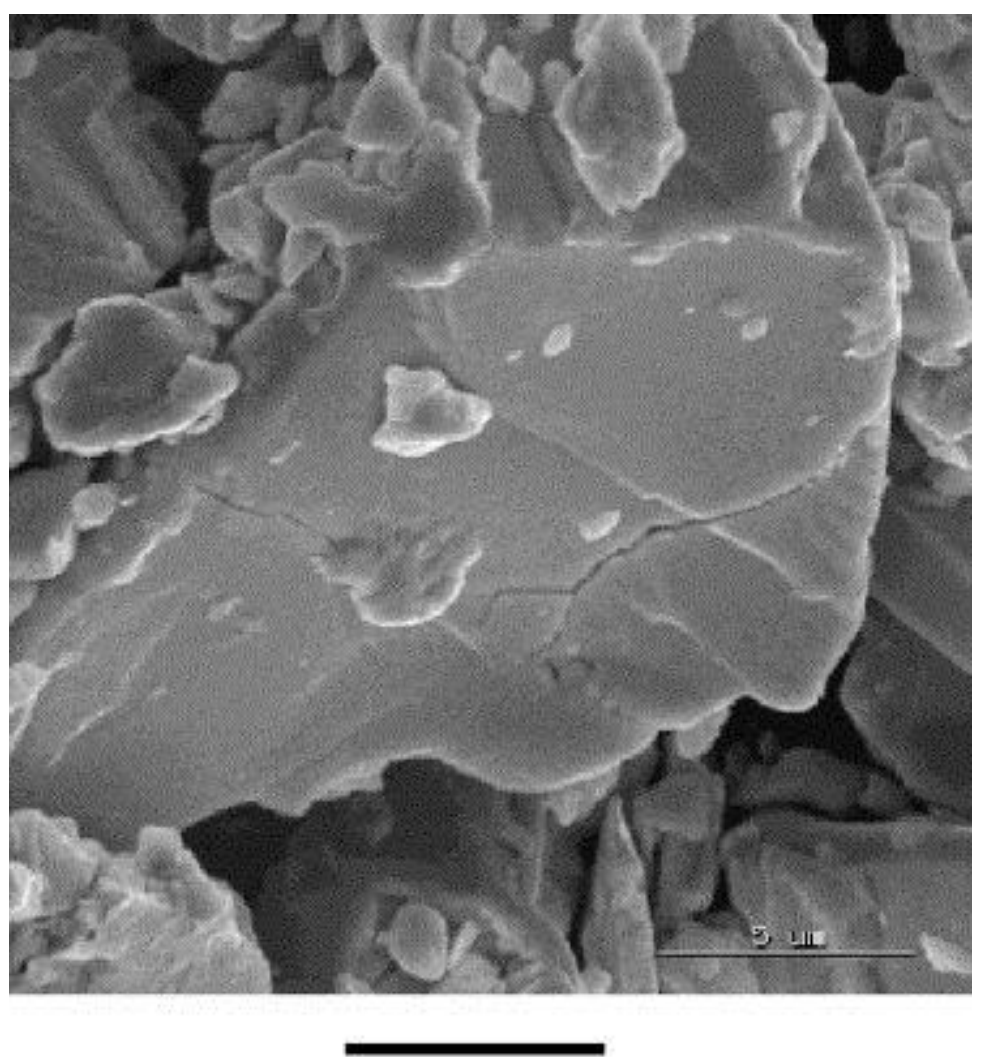

$5 \mu \mathrm{m}$

Fig. 4. Evidence of the brittleness of the material ground under $\mathrm{H}_{2}$. See the straight fracture. 

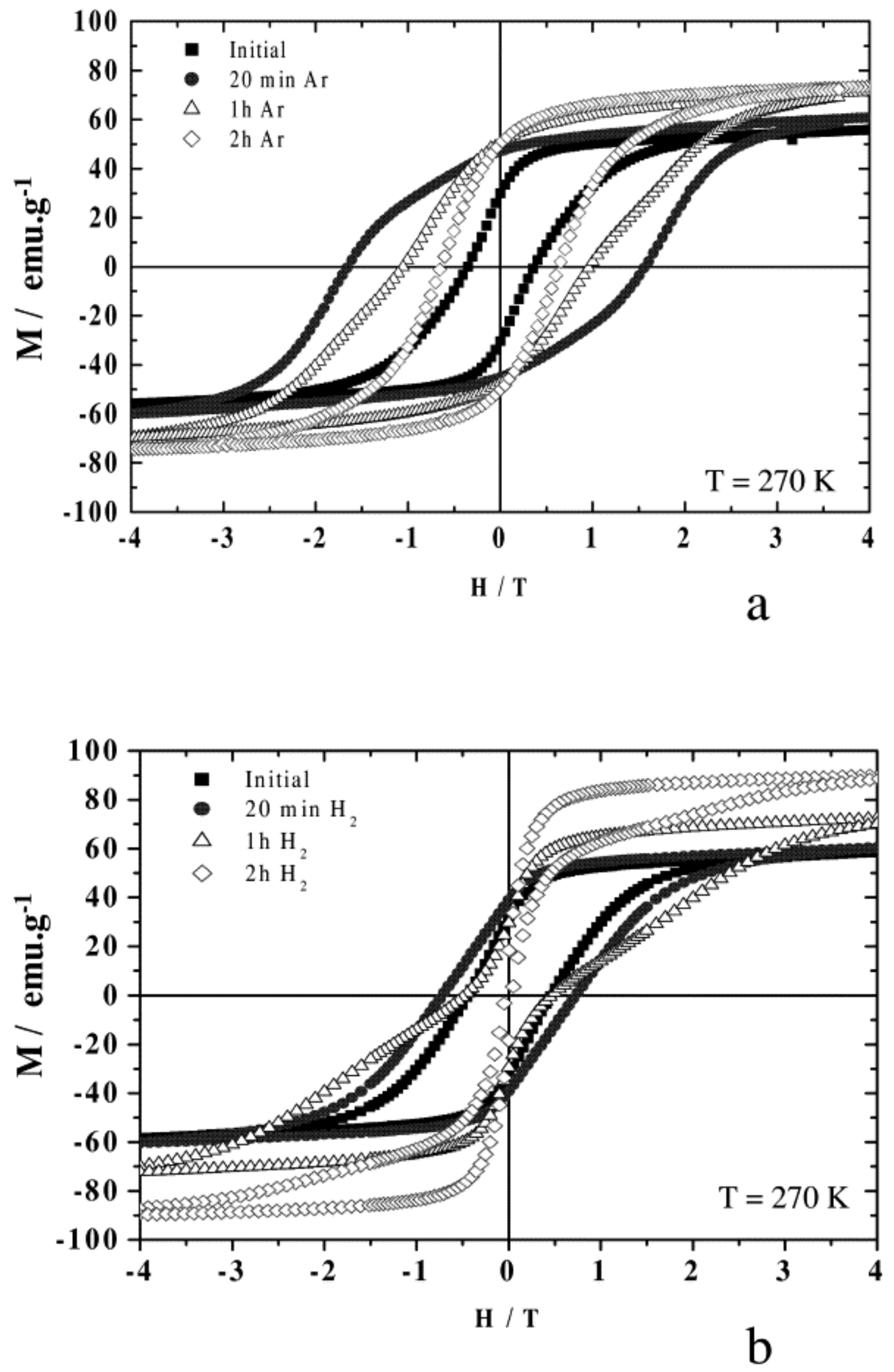

Fig. 5. Magnetic properties of the samples ground under $\operatorname{Ar}(a)$ or $\mathrm{H}_{2}$ (b). 
Table 1. Size of $\mathrm{SmCo}_{5}$ particles ground under $\mathrm{Ar}$ or $\mathrm{H}_{2}$

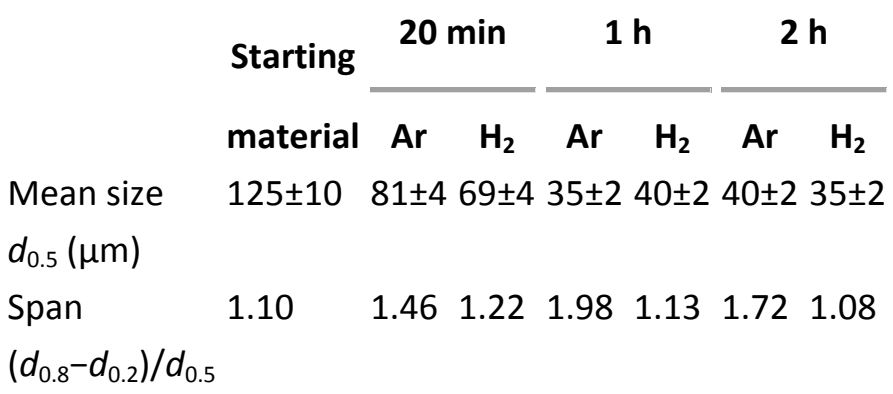

Table 2. Coercivity and saturation magnetization of the samples ground under $\mathrm{Ar}$ or $\mathrm{H}_{2}$

\begin{tabular}{|c|c|c|c|c|c|}
\hline & $20 \mathrm{~min}$ & 11 & h & & $\mathrm{h}$ \\
\hline terial & Ar $\mathrm{H}_{2}$ & $\mathrm{Ar}$ & $\mathbf{H}_{2}$ & $\mathrm{Ar}$ & $\mathrm{H}_{2}$ \\
\hline & 1.60 .7 & 1.0 & 0.4 & 0.6 & 0.0 \\
\hline & $60 \quad 62$ & 71 & 71 & 73 & 91 \\
\hline
\end{tabular}

